\title{
Potential Risk Factors and Incidence of Pulmonary Thromboembolism in Japan Results From an Overview of Mailed Questionnaires and a Matched Case-Control Study
}

\author{
Koichiro Sugimura, MD; Masahito Sakuma, MD; Kunio Shirato, MD
}

\begin{abstract}
Background The potential risk factors for pulmonary thromboembolism (PTE) have not been examined in Japan, so the aims of the present study were to assess independent risk factors for PTE, and to estimate the recent incidence of symptomatic PTE.

Methods and Results Based on a mailed questionnaire, the potential risk factors for PTE were prospectively assessed using a matched case-control study, and the number of new patients with PTE in 2004 was calculated prospectively. In multivariate analyses, increase in body mass index (odds ratio (OR) $=2.85$ by $10 \mathrm{~kg} / \mathrm{m}^{2} ; 95 \%$ confidence interval (CI), 1.51-5.39), prolonged immobilization (OR, 8.14; 95\% CI, 3.15-20.99), recent major surgery (OR, 6.78; 95\% CI, 2.65-17.32), and cancer (OR, 2.72; 95\% CI, 1.25-5.95) were identified as independent risk factors for PTE in Japan. The risks for atherosclerosis (diabetes mellitus, hypertension, hyperlipidemia, and smoking), and alcohol consumption did not affect the incidence of PTE. The calculated number of new patients with PTE per year was 4,108 (95\% CI, 3,564-4,712) in 2004.

Conclusion The independent risk factors for PTE in Japan are body mass index, prolonged immobilization, recent major surgery, and cancer. The number of new patients with PTE in 2004 did not demonstrate an upward trend compared with 2000. (Circ J 2006; 70: 542-547)
\end{abstract}

Key Words: Body mass index; Cancer; Immobilization; Pulmonary thromboembolism; Surgery

D eaths from pulmonary thromboembolism (PTE) have increased in Japan annually! The numbers of symptomatic PTE patients were estimated in both 1996 and 2000, and tended to increase between those years 2,3 Independent risk factors for PTE were proposed in the United States, and their incidence in Japan has been reported;2,3,5 however, the odds ratio (OR) of each factor has not been examined in Japan. Moreover, it is controversial whether cardiovascular risk factors are causally related to PTE6-8

Our aims for this present study were to assess the potential risk factors for PTE and to estimate the recent incidence of symptomatic PTE per year in Japan.

\section{Methods}

The present study was approved by the Ethics Committee of Tohoku University. In July 2004, we sent questionnaires to the clinical departments (all departments of internal medicine, surgery, pediatrics, psychiatry, obstetrics and gynecology, orthopedics, otorhinolaryngology, ophthalmology, dermatology and urology) of university schools of medicine or medical colleges and to hospitals with more

(Received November 2, 2005; revised manuscript received February 20, 2006; accepted February 27, 2006)

Department of Cardiovascular Medicine, Tohoku University Graduate School of Medicine, Sendai, Japan

Mailing address: Masahito Sakuma, MD, Department of Cardiovascular Medicine, Tohoku University Graduate School of Medicine, 1-1 Seiryo-machi, Aoba-ku, Sendai 980-8574, Japan. E-mail: sakuma @ cardio.med.tohoku.ac.jp than 100 beds in Japan. Based on the replies, we prospectively assessed the number of new patients with PTE from August 1, 2004 to September 30, 2004 and the potential risk factors for PTE (obesity, prolonged immobilization, recent major surgery, pregnancy/postpartum, recent major trauma/fracture, cancer, coagulation disorders, diabetes mellitus, hypertension, hyperlipidemia, smoking, and drinking). Each case of PTE was paired with a control case without PTE (matched for gender and age within 5 years, and admitted closest after the case). Alcohol consumption was calculated as $\mathrm{g} /$ day $=$ amount of drink $(\mathrm{ml} /$ day $) \times$ concentration of alcohol $(\%) \times 0.8(\mathrm{~g} / \mathrm{ml}) / 100$, where the concentration of alcohol in beer, wine, sake, shochu (Japanese distilled liquor), and whisky is $5 \%, 12 \%, 15 \%, 25 \%$, and $40 \%$, respectively, and 0.8 is the specific gravity of alcohol. The number of patients with PTE per year was calculated as the number of patients with PTE per year $=$ the number of patients with PTE per 2 months $\times 6 /$ the response rate.

\section{Definition of Terms}

PTE was definitely diagnosed by (1) enhanced computed tomography, (2) pulmonary angiography, (3) pulmonary perfusion scintigraphy and/or pulmonary ventilation scintigraphy, (4) magnetic resonance imaging, or (5) autopsy. Acute PTE was defined as acute onset of less than 2 weeks. Chronic thromboembolic pulmonary hypertension (CTEPH) was defined as stable pulmonary thromboembolic lesions for 6 months or longer with a mean pulmonary artery pressure greater than $25 \mathrm{mmHg}$, and pulmonary capillary wedge pressure less than $12 \mathrm{mmHg}$., 10 Chronic PTE was the cases that did not satisfy the criteria for acute PTE or CTEPH and 
Table 1 Prognosis of Pulmonary Thromboembolism

\begin{tabular}{lcccccc}
\hline \hline & \multicolumn{2}{c}{ Acute } & $\begin{array}{c}\text { Chronic } \\
(n=17)\end{array}$ & $\begin{array}{c}\text { CTEPH } \\
(n=2)\end{array}$ & $\begin{array}{c}\text { Recurrent } \\
(n=4)\end{array}$ & $\begin{array}{c}\text { Unclassified } \\
(n=17)\end{array}$ \\
\cline { 2 - 7 } & $\begin{array}{c}\text { In-hospital } \\
(n=104 * 1)\end{array}$ & $\begin{array}{c}\text { Out-hospital } \\
(n=65 * 2)\end{array}$ & 0 & 0 & 1 & 0 \\
\hline 30-day death & $25(25 \%)$ & $11(17 \%)$ & & 0 & 0 & 0 \\
$\quad$ Fiuse of death & 19 & 6 & 0 & 0 & 1 & 0 \\
$\quad \begin{array}{l}\text { Recurrent attack } \\
\text { Pre-existing disease }\end{array}$ & 4 & 2 & 0 & 0 & 0 & 0 \\
$\quad$ Intracranial bleeding & 1 & $2 * 3$ & 0 & 0 & 0 & 0 \\
\hline
\end{tabular}

${ }^{*}$ Two of 104 cases were missed 30 days after diagnosing pulmonary thromboembolism. ${ }^{* 2}$ Two of 65 cases were missed. ${ }^{* 3}$ One with cancer, ${ }^{* 4}$ one with pneumonia and one with congestive heart disease. CTEPH, choronic thromboembolic pulmonary hypertension.

Table 2 Univariate Conditional Logistic Analyses of Potential Risk Factors for Pulmonary Thromboembolism

\begin{tabular}{|c|c|c|c|c|c|c|c|}
\hline & \multicolumn{4}{|c|}{ Case-control pairs, no. $* 1$} & \multirow{2}{*}{ Odds ratio } & \multirow{2}{*}{$(95 \% C I)$} & \multirow{2}{*}{ p-value } \\
\hline & $+/+$ & $+/-$ & $-1+$ & $-1-$ & & & \\
\hline$B M I\left(10 \mathrm{~kg} / \mathrm{m}^{2}\right)$ & & & & & 2.37 & $(1.44-4.01)$ & 0.0004 \\
\hline Prolonged immobilization & 9 & 50 & 7 & 142 & 7.14 & $(3.22-18.67)$ & $<0.0001$ \\
\hline Recent major surgery & 26 & 46 & 10 & 126 & 4.60 & $(2.29-10.22)$ & $<0.0001$ \\
\hline Pregnancy or postpartum & 2 & 3 & 1 & 134 & 3.00 & $(0.24-157.5)$ & 0.63 \\
\hline Recent major trauma and/or fracture & 3 & 18 & 3 & 184 & 6.00 & $(1.75-31.8)$ & 0.002 \\
\hline Cancer & 18 & 31 & 16 & 143 & 1.94 & $(1.03-3.79)$ & 0.04 \\
\hline Coagulation disorders & 1 & 5 & 3 & 199 & 1.67 & $(0.32-10.73)$ & 0.73 \\
\hline
\end{tabular}

${ }^{*}+/+$, indicates that both the case and the control had the characteristic; +/-, that the case had the characteristic while the control did not; -/+, that the case did not have the characteristic while the control did; -/-, that neither the case nor the control had the characteristic. BMI, body mass index.

Table 3 Chronic Diseases and Personal Habits

\begin{tabular}{|c|c|c|c|c|c|c|c|}
\hline & \multicolumn{4}{|c|}{ Case-control pairs, no. ${ }^{* 1}$} & \multirow{2}{*}{ Odds ratio } & \multirow{2}{*}{$(95 \% C I)$} & \multirow{2}{*}{$p$-value } \\
\hline & $+/+$ & $+/-$ & $-1+$ & $-/-$ & & & \\
\hline \multicolumn{8}{|l|}{ Diabetes mellitus } \\
\hline All pairs & 9 & 21 & 29 & 145 & 0.72 & $(0.39-1.31)$ & 0.32 \\
\hline Selected pairs & 3 & 18 & 18 & 88 & 1.00 & $(0.49-2.04)$ & 1.00 \\
\hline \multicolumn{8}{|l|}{ Hypertension } \\
\hline All pairs & 87 & 34 & 45 & 74 & 0.76 & $(0.47-1.21)$ & 0.26 \\
\hline Selected pairs & 30 & 21 & 26 & 51 & 0.81 & $(0.43-1.49)$ & 0.56 \\
\hline \multicolumn{8}{|l|}{ Hyperlipidemia } \\
\hline All pairs & 13 & 35 & 35 & 119 & 1.00 & $(0.61-1.65)$ & 1.00 \\
\hline Selected pairs & 6 & 21 & 15 & 83 & 1.40 & $(0.69-2.92)$ & 0.41 \\
\hline \multicolumn{8}{|l|}{ Smoking $* 2$} \\
\hline All pairs & & & & & 0.93 & $(0.62-1.38)$ & 0.78 \\
\hline Selected pairs & & & & & 0.93 & $(0.62-1.38)$ & 0.78 \\
\hline \multicolumn{8}{|l|}{ Drinking*3 } \\
\hline All pairs & & & & & 1.00 & $(0.62-1.61)$ & 1.00 \\
\hline Selected pairs & & & & & 1.00 & $(0.62-1.61)$ & 1.00 \\
\hline
\end{tabular}

${ }^{* I}+/+$, indicates that both the case and the control had the characteristic; +/-, that the case had the characteristic while the control did not; -/+, that the case did not have the characteristic while the control did; -/-, that neither the case nor the control had the characteristic.

${ }^{*}{ }^{2}$ We gave a score of 0 to non-smokers, 1 to ex-smokers ( $\geq 3$ months), and 2 to current smokers for conditional logistic regression. ${ }^{*}$ We gave a score of 0 to non-drinkers, 1 to occasional drinkers, and 2 to drinkers for conditional logistic regression. Selected pairs indicate excluding pairs in which control admitted due to coronary artery disease, lung cancer, diabetes mellitus, or hypertension.

included the subacute type in which acute onset of PTE is diagnosed late, and acute-with-chronic type in which the patient complains of slight symptoms for a long time before having an acute episode ${ }^{11}$ Recurrent PTE was defined as acute onset illness of less than 2 weeks with a past history of acute PTE. Finally, unclassified PTE was defined as the cases that did not fit any of the preceding categories according to the participating doctor. Major surgery was defined as abdominal surgery and/or surgery lasting more than 45 min within the previous 3 months! ${ }^{12-14}$ Immobiliza- tion was defined as strict bed rest for longer than 3 continuous days within the previous 3 months ${ }^{14}$

\section{Statistical Analysis}

Analyses were performed using SPSS 13.0 (SPSS Inc, Chicago, IL, USA), and StatXact 6 and LogXact 6 (Cytel Software Corporation, Cambridge, MA, USA). All continuous variables were analyzed by Mann-Whitney test and expressed as mean \pm standard deviation. Potential risk factors for acute PTE were assessed using conditional logis- 
Table 4 Laboratory Date

\begin{tabular}{|c|c|c|c|}
\hline & Case & Control & p-value \\
\hline \multicolumn{4}{|c|}{ Fasting blood glucose $(\mathrm{mg} / \mathrm{dl})$} \\
\hline All pairs & $120 \pm 59$ & $113 \pm 40$ & 0.11 \\
\hline Selected pairs & $121 \pm 60$ & $111 \pm 34$ & 0.09 \\
\hline \multicolumn{4}{|c|}{ Systolic blood pressure $(\mathrm{mmHg})$} \\
\hline All pairs & $125 \pm 17$ & $126 \pm 17$ & 0.26 \\
\hline Selected pairs & $125 \pm 16$ & $127 \pm 18$ & 0.48 \\
\hline \multicolumn{4}{|c|}{ Diastolic blood pressure $(\mathrm{mmHg})$} \\
\hline All pairs & $73 \pm 12$ & $73 \pm 13$ & 0.39 \\
\hline Selected pairs & $73 \pm 12$ & $73 \pm 11$ & 0.94 \\
\hline \multicolumn{4}{|c|}{ Total cholesterol $(\mathrm{mg} / \mathrm{dl})$} \\
\hline All pairs & $186 \pm 49$ & $191 \pm 50$ & 0.71 \\
\hline Selected pairs & $184 \pm 52$ & $185 \pm 53$ & 0.73 \\
\hline \multicolumn{4}{|c|}{ HDL-cholesterol $(\mathrm{mg} / \mathrm{dl})$} \\
\hline All pairs & $50 \pm 44$ & $52 \pm 28$ & 0.11 \\
\hline Selected pairs & $47 \pm 24$ & $53 \pm 36$ & 0.24 \\
\hline \multicolumn{4}{|c|}{ Triglycerides $(\mathrm{mg} / \mathrm{dl})$} \\
\hline All pairs & $117 \pm 53$ & $128 \pm 84$ & 0.51 \\
\hline Selected pairs & $118 \pm 59$ & $121 \pm 81$ & 0.79 \\
\hline
\end{tabular}

$H D L$, high-density lipoprotein.

tic regression and the results are presented as estimated OR with the corresponding 95\% confidence intervals (CI). All significant tests were 2 -tailed, with $\mathrm{p}<0.05$ considered as statistically significant.

\section{Results}

A total of 6,321 questionnaires were sent, but 18 institutes were excluded from the analysis because they had closed or merged. We received 1,878 valid replies, giving a response rate of $29.8 \%(1,879 / 6,303)$. The response rate was $36.0 \%$ for universities and $26.3 \%$ for hospitals. We registered 209 cases (acute $=169$, chronic $=17, \mathrm{CTEPH}=2$, recurrent $=4$, and unclassified $=17$ ) for the case-control study. Five cases were excluded from the calculation of the incidence of PTE, because the occurrence of disease differed from the stated period. The rates of PTE cases were $6.9 \%$ for universities and $8.4 \%$ for hospitals. The number of registered cases was 79 ( 0.0958 cases/institute) in universities and 125 ( 0.1186 cases/institute) in hospitals.

\section{Case-Control Results}

There were 209 case-control pairs (69 men pairs, 140 women pairs) and the respective ages and body mass index (BMI) for the cases and controls were 64.7 \pm 14.9 and $64.3 \pm 15.2$ years $(\mathrm{p}=0.16)$, and $24.4 \pm 5.0 \mathrm{~kg} / \mathrm{m}^{2}$ and $22.8 \pm$ $3.8(\mathrm{p}=0.001)$. BMI $\geq 25$ was found in 69 of 196 cases $(35.2 \%)$ and in 54 of 209 controls $(25.8 \%)$ and $\geq 30$ in 20 of the cases $(10.2 \%)$ and in 10 of the controls (4.8\%). The 30-day mortality and causes of death are shown in Table 1. The 30-day mortality for all PTE and the acute PTE cases was $18.0 \%$ and $22.1 \%$, respectively.

In the univariate analyses, BMI (OR, 2.37 (per $10 \mathrm{~kg} / \mathrm{m}^{2}$ increase); 95\% CI, 1.44-4.01), prolonged immobilization (OR, 7.14; 95\% CI, 3.22-18.67), recent major surgery (OR, $4.60 ; 95 \% \mathrm{CI}, 2.29-10.22)$, recent major trauma and/or recent major fracture $(\mathrm{OR}, 6.00 ; 95 \% \mathrm{CI}, 1.75-31.8)$, and cancer (OR, 1.94; n 95\% CI, 1.03-3.79) were significant risk factors (Table 2). Oral contraceptive was excluded from the analysis because only 1 subject had used contraceptives ( 1 of the cases and none of the controls). Diabetes mellitus, hypertension, hyperlipidemia, smoking, and drinking were not significant risk factors in either all (person)
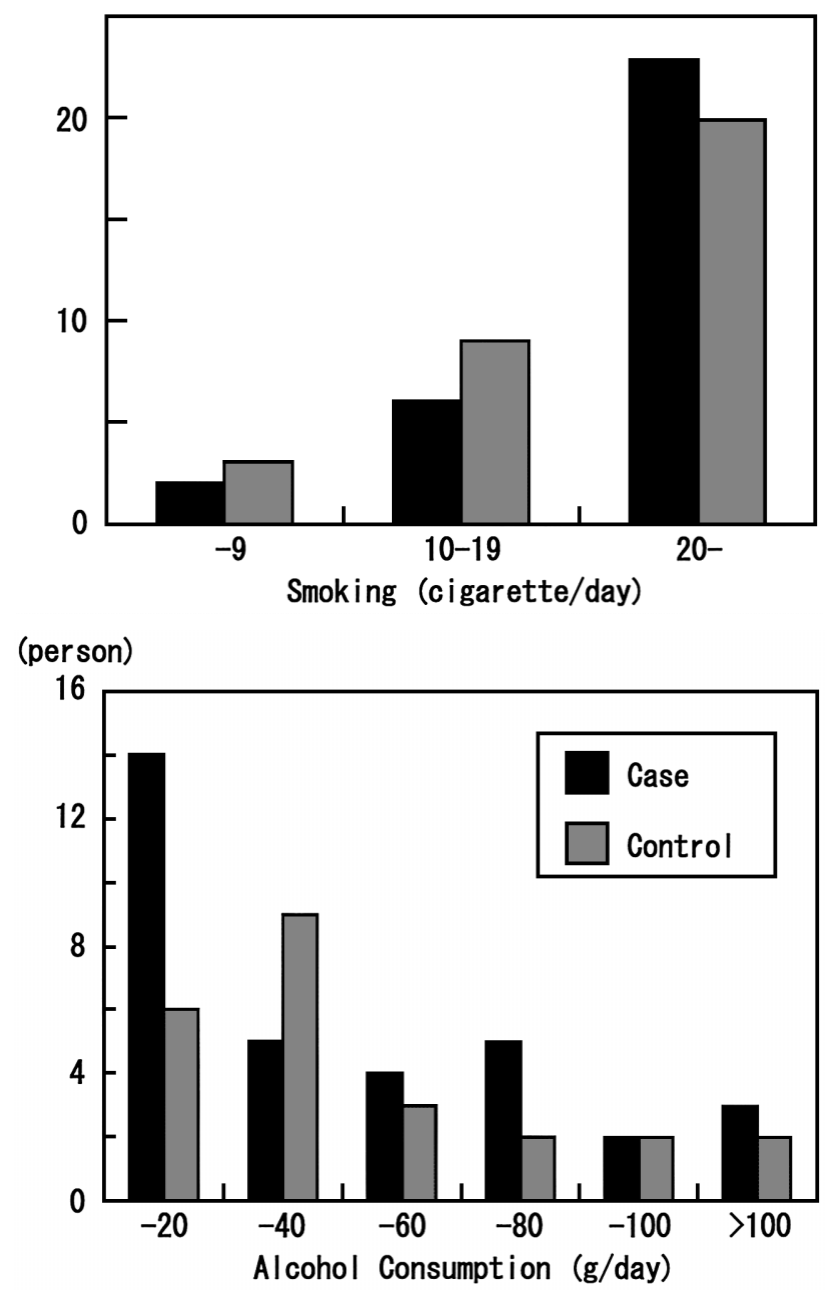

Fig 1. Levels of smoking in current smokers and alcohol consumption in drinkers. $\mathrm{p}=0.61$ and $\mathrm{p}=0.45$ respectively.

matched-pairs or selected pairs excluding those in which the controls were admitted because of coronary artery disease, lung cancer, diabetes mellitus, or hypertension (Table 3). There were no significant differences in fasting blood sugar, mean blood pressure, total cholesterol or triglycerides (Table 4). The levels of smoking in current smokers and alcohol consumption in drinkers are shown in Fig 1.

Deep vein thrombosis was proved in only 62 cases $(29.8 \%)$. As an additional potential risk, antipsychotic agents were reported in 6 cases, steroid use in 6 cases, varicose veins in 3 cases, chemotherapy in 2 cases, and an association with travel in 2 cases.

In the multivariate analysis, BMI (OR, 2.85 (per $10 \mathrm{~kg} / \mathrm{m}^{2}$ increase); 95\% CI, 1.51-5.39), prolonged immobilization (OR, 8.14; 95\% CI, 3.15-20.99), recent major surgery (OR, 6.78; 95\% CI, 2.67-17.32), and cancer (OR, 2.72; 95\% CI, 1.25-5.95) were independent risk factors for PTE (Table 5).

\section{Incidence of PTE}

The number of new patients with PTE was 204 ( 0 in 1,733 institutes, 1 in 104, 2 in 29, 3 in 10, and 4 in 3 ) during the 2 months of the present study period (69 men, 135 women; mean age 64.8 \pm 15.1 years; excluding cases diag- 
nosed as PTE before August 1, 2004 or after September 30, 2004).

The estimated number of new patients with PTE per year was 4,108 (95\% CI, 3,564-4,712) and the incidence of PTE was 32.2 (95\% CI, 27.9-36.9) patients per 1,000,000 people per year in Japan.

\section{Discussion}

\section{Risk Factors for PTE}

The results of the present study shows that the independent risk factors for PTE in Japan are BMI, prolonged immobilization, recent major surgery, and cancer.

The larger BMI is, the higher the risk for PTE. The Japanese Society of Pulmonary Embolism Research (JaSPER) reported that BMI was greater in PTE patients than that in the general population ${ }^{15}$ which indicates that obesity is a risk for PTE also in Japan where extreme obesity is less than in Western countries!6 Many Western reports have demonstrated that obesity is one of the risk factors for PTE, 6,17 although Hansson et al reported that an increase in BMI was not a risk, rather an increase in waist circumference ${ }^{18}$ Venous congestion and an imbalance of both coagulation and fibrolytic activity have been thought of as mechanisms by which obesity became a risk for PTE. Conversely, if obesity is decreased, coagulation and fibrolytic activity are improved. Primrose et al indicated that, after surgical treatment for excessive obesity, levels of factor VII, fibrinogen and plasminogen activator inhibitor type-1 that were elevated before surgery were lowered, and activity of tissue plasminogen activator that was previously undetected was increased and normalized 19 Male obesity has been increasing in Japan, ${ }^{16}$ so reducing obesity is important for the prevention not only of coronary artery disease and cerebral vascular disease but also PTE.

Prolonged immobilization, recent major surgery, and cancer were risk factors for PTE in the present study and have been known as potential risks for PTE in Western countries. In Japan, PTE occurred in $0.05 \%$ of all surgeries $(440 / 925,260)$, and the mortality was $18.9 \%$ ? As for major surgery, PTE occurred in $1.15 \%$ of thoracic surgeries, and in $0.32 \%$ of abdominal surgeries ${ }^{21}$ These incidences are higher than the present incidence of PTE in the whole population of Japan $(0.0032 \%)$.

Western studies have shown that PTE is increased not only by cancer itself but also by anticancer drugs $2^{2}$ The incidence is higher in cancer surgery than in non-cancer surgery also in Japan (1.55\% vs $0.20 \%)^{21}$ However, the degree of risk of cancer for PTE had not been reported in Japan and the present data indicate that cancer and surgery are independent risk factors for PTE.

Pregnancy or the postpartum period, and recent major trauma and/or recent major fracture did not constitute significant risk factors. One of the reasons may be the small number of cases with these factors. The incidence of PTE is $0.02 \%$ of all deliveries and $0.06 \%$ of cesarean births in Japan ${ }^{23}$ which are higher than the incidence of PTE in the whole population $(0.0032 \%)$. In orthopedics, total knee replacement and total hip replacement augment the incidence of PTE ${ }^{24}$ And the rate of deep vein thrombosis after major joint surgery without prophylaxis in Asian patients is similar to that in Western countries. ${ }^{25}$ However, there are no reports assessing the independent risk of trauma and/or fracture for PTE in Japan, excluding the effect of surgery. Further examination is needed to clarify the risk factors for
Table 5 Multivariate Conditional Logistic Analyses of Potential Risk Factors for Pulmonary Thromboembolism

\begin{tabular}{lcccc}
\hline \hline & $\begin{array}{l}\text { Odds } \\
\text { ratio }\end{array}$ & $(95 \% \mathrm{CI})$ & p-value \\
\hline Body mass index $\left(10 \mathrm{~kg} / \mathrm{m}^{2}\right)$ & 2.85 & $(1.51-5.39)$ & 0.001 \\
Prolonged immobilization & 8.14 & $(3.15-20.99)$ & $<0.0001$ \\
Recent major surgery & 6.78 & $(2.65-17.32)$ & $<0.0001$ \\
Recent major trauma and/or fracture & 3.57 & $(0.86-14.78)$ & 0.08 \\
Cancer & 2.72 & $(1.25-5.95)$ & 0.01 \\
\hline
\end{tabular}

PTE in obstetrics and orthopedics.

Oral contraceptive use is a risk for PTE in Western countries, ${ }^{26}$ but excluded from our analysis, because there was only 1 case in the present study, reflecting the low use in Japan.

In the present study, smoking, alcohol consumption, hyperlipidemia, hypertension and diabetes mellitus were not risks for PTE. Previous findings are controversial about whether the risks for atherosclerosis are also those for venous thromboembolism. As for smoking, some have shown it to be a risk for PTE, 18,27 but others have not, $6,8,28$ Pahor et al indicated that an increase in alcohol consumption reduced the risk ${ }^{28}$ but Tsai did not recognize a significant relation between the amount of alcohol consumed and risk? In a case-control study, hypercholesterolemia was a risk for deep vein thrombosis, ${ }^{29}$ but Lippi et al failed to demonstrate an association 30 On the other hand, von Depka et al suggested that increased lipoprotein (a) was an independent risk factor for venous thromboembolism? ${ }^{1}$ Detailed evaluations of US communities showed that total cholesterol, high-density lipoprotein cholesterol, low-density lipoprotein cholesterol and lipoprotein (a) were not risk factors for venous thromboembolism, and that, compared with a triglyceride level of less than $91 \mathrm{mg} / \mathrm{dl}$, only levels from 91 to less than 140 increased the risk for venous thromboembolism? Hypertension has been identified as a risk? but not confirmed, ${ }^{6,8}$ and similarly for diabetes mellitus ${ }^{6-8}$ Further studies are needed to reach a conclusion on the relationship between venous thromboembolism and the risks for atherosclerosis.

\section{Mortality From PTE}

The 30-day mortality rate from acute PTE $(22.1 \%)$ in all of Japan obtained in the present survey was high compared with recent data from JaSPER $(8.0 \%)^{32}$ and a possible reason for the difference is the treatment regimens. However, a reduction in the mortality from PTE in Japan can result from an increment in the number of diagnosed cases of minor PTE 32 so another possible reason was insufficient diagnosis of minor PTE in the present survey. On the other hand, 30-day mortality from all types of PTE was 18.0\% in the present study, which was similar to that in the 2000 survey $(16 \%)$ ?

\section{Incidence of PTE}

There was no apparent increase in the number of clinically diagnosed patients in the data from 2000 ?

In the United States, age-adjusted mortality from PTE is 0.9 cases per 100,000 per year in non-black, non-white Americans 33 and approximately 0.8 per 100,000 in Japan! The difference is small but the clinical cases between the 2 populations differed: 7 diagnoses in 100,000 people per year in non-black, non-white Americans ${ }^{34}$ and 3.22 in Japan in 2004. The difference in the number of clinical 
cases may relate to a difference in the diagnostic power for PTE between Japan and the United States.

The diagnostic power of PTE in Japan is thought to have improved in selected institutes ${ }^{35}$ On the other hand, in institutes actively preventing venous thromboembolism, deep vein thrombosis was found more often than before, but the incidence of PTE was decreasing. 36 These facts may be responsible for the unchanged incidence of PTE as a whole compared with that in 2000.

The prevalence of PTE in 2002 was 6,000 patients per year, based on the patient survey by the Ministry of Health, Labour and Welfare, Japan ${ }^{37}$ This is larger than our estimation, but a simple comparison between our results and the prevalence cannot be made because our data included the incidence, whereas the data from the national government were estimated in 1,000's.

\section{Study Limitations}

We selected potential risks thought have a high incidence. Therefore, we did not assess central venous catheters, catheter examination/therapy, congestive heart disease, and varicose veins. With further studies it will be possible to assess these factors as risks for PTE.

The response rates for questionnaires regarding less common diseases are low in general. The response rate of studies on the incidence of PTE performed by us was $40.7 \%(2,341 / 5,748)$ in $1996,30.6 \%(1,702 / 5,565)$ in 2000 , and $29.8 \%(1,878 / 6,303)$ in the present study. When the response rate is $100 \%$, the number of patients is made up from questionnaires. But if not, random return of questionnaires is necessary to estimate the number of patients. A low response rate may give the assumption some bias. Therefore, a low response rate is one of our study limitations.

Seasonal variation in the occurrence of PTE was not taken into consideration when calculating the incidence of PTE. However, the existence of such variation is controversial ${ }^{38,39}$ In a previous study of a small number of cases we could not find a seasonal variation in Japan. ${ }^{40}$

\section{Conclusion}

The independent risk factors for PTE in Japan are BMI, prolonged immobilization, recent major surgery, and cancer. The estimated number of newly diagnosed patients with PTE per year was 4,108 $(95 \% \mathrm{CI}, 3,564-4,712)$ in 2004, and did not apparently increase from that in 2000.

\section{Acknowledgments}

We thank all of the institutions that replied to our mailed questionnaires. This study was partly supported by a grant from the Respiratory Failure Research Group from the Ministry of Health, Labour and Welfare, Japan.

\section{References}

1. Sakuma M, Konno Y, Shirato K. Increasing mortality from pulmonary embolism in Japan, 1951-2000. Circ J 2002; 66: 1144-1149.

2. Kumasaka N, Sakuma M, Shirato K. Incidence of pulmonary thromboembolism in Japan. Jpn Circ J 1999; 63: 439-441.

3. Kitamukai O, Sakuma M, Takahashi T, Kagaya Y, Watanabe J, Shirato K. Incidence and characteristics of pulmonary thromboembolism in Japan 2000. Intern Med 2003; 42: 1090-1094.

4. Heit JA, Silverstein MD, Mohr DN, Petterson TM, O'Fallon WM, Melton LJ 3rd. Risk factors for deep vein thrombosis and pulmonary embolism: A population-based case-control study. Arch Intern Med 2000; 160: 809-815.

5. Nakamura M, Fujioka H, Yamada N, Sakuma M, Okada O, Nakanishi $\mathrm{N}$, et al. Clinical characteristics of acute pulmonary embolism in
Japan: Results of a multicenter registry in Japanese Society of Pulmonary Embolism Research. Clin Cardiol 2001; 24: 132-138.

6. Goldhaber SZ, Savage DD, Garrison RJ, Castelli WP, Kannel WB, McNamara PM, et al. Risk factors for pulmonary embolism: The Framingham Study. Am J Med 1983; 74: 1023-1028.

7. Goldhaber SZ, Grodstein F, Stampfer MJ, Manson JE, Colditz GA, Speizer FE, et al. A prospective study of risk factors for pulmonary embolism in women. JAMA 1997; 277: 642-645.

8. Tsai AW, Cushman M, Rosamond WD, Heckbert SR, Polak JF, Folsom AR. Cardiovascular risk factors and venous thromboembolism incidence: The longitudinal investigation of thromboembolism etiology. Arch Intern Med 2002; 162: 1182-1189.

9. Daily PO, Dembitsky WP, Peterson KL, Moser KM. Modification of techniques and early results of pulmonary thromboendarterectomy for chronic pulmonary embolism. J Thorac Cardiovasc Surg 1987; 93: $221-233$.

10. Simonneau G, Arzarian R, Brenot F, Dartevelle PG, Musset D, Duroux P. Surgical management of unresolved pulmonary embolism: A personal series of 72 patients. Chest 1995; 107: 52S-55S.

11. Sakuma M, Nakamura M, Nakanishi N, Miyahara Y, Tanabe N, Yamada N, et al. Clinical characteristics, diagnosis and management of patients with pulmonary thromboembolism who were not diagnosed in acute phase and not classified as chronic thromboembolic pulmonary hypertension. Circ J 2005; 69: 1009-1015.

12. Nicolaides A, Breddin H, Fareed J, Goldhaber S, Haas S, Hull R, et al. Prevention of venous thromboembolism: International Consensus Statement: Guidelines compiled in accordance with the scientific evidence. Int Angiol 2001; 20: 1-37.

13. Heit JA, Silverstein MD, Mohr DN, Petterson TM, O'Fallon WM, Melton LJ 3rd. Predictors of survival after deep vein thrombosis and pulmonary embolism. Arch Intern Med 1999; 159: 445-453.

14. Quinn DA, Thompson BT, Terrin ML, Thrall JH, Athanasoulis CA, McKusick KA, et al. A prospective investigation of pulmonary embolism in women and men. JAMA 1992; 268: 1689-1696.

15. Sakuma M, Takahashi T, Demachi J, Suzuki J, Nawata J, Kakudo N, et al. Epidemiology of pulmonary embolism in Japan. In: Shirato K, editor. Venous thromboembolism: Prevention and treatment. Tokyo: Springer; 2005; 3-12.

16. Tanaka H, Kokubo Y. Epidemiology of obesity. J Jpn Med Assoc 2003; 130: 25-30 (in Japanese)

17. Stein PD, Beemath A, Olson RE. Obesity as a risk factor in venous thromboembolism. Am J Med 2005; 118: 978-980.

18. Hansson PO, Eriksson H, Welin L, Svardsudd K, Whihelmsen L. Smoking and abdominal obesity: Risk factors for venous thromboembolism among middle-aged men: "The study of men born in 1913". Arch Intern Med 1999; 159: 1886-1890.

19. Primrose JN, Davies JA, Prentice CRM, Hughes R, Johnstone D. Reduction in factor VII, fibrinogen and plasminogen activator inhibitor-1 activity after surgical treatment of morbid obesity. Thromb Haemost 1992; 68: 396-399.

20. Kuroiwa M, Furuya H, Seo N, Irata K, Sawa T, Sasaki J, et al. Incidence and characteristics of perioperative pulmonary thromboembolism in Japan in 2003. Masui 2005; 54: 822-828.

21. Sakon M, Ikeda M, Hata Y, Suzuki R, Sekimoto M, Monden M. Incidence and the prevention of venous thromboembolism in Japan: General surgery. In: Shirato K, editor. Venous thromboembolism: Prevention and treatment. Tokyo: Springer; 2005; 119-124.

22. Levine M, Gent M, Hirsh J, Amold A, Goodyear MD, Hryniuk W, et al. The effect of anticancer drug therapy in women with stage II breast cancer. $N$ Engl J Med 1988; 318: 404-407.

23. Kobayashi T, Nakabayashi M, Ishikawa M, Ikenoue T, Adachi T, Kobashi G, et al. Final reports of deep vein thrombosis/pulmonary thromboembolism between 1991 and 2000 in obstetrics and gynecology. Jpn J Obstet Gynecol Neonatal Hematol 2005; 142: 1-24.

24. Fujita $S$. Incidence and prevention of venous thromboembolism in orthopedic surgery in Japan. In: Shirato K, editor. Venous thromboembolism: Prevention and treatment. Tokyo: Springer; 2005; $125-132$.

25. Piovella F, Wang CJ, Lu H, Lee K, Lee LH, Lee WC, et al. Deep vein thrombosis rates after major orthopedic surgery in Asia: An epidemiological study based on postoperative screening with centrally adjudicated bilateral venography. J Thromb Haemost 2005; 3: $2664-2670$.

26. Helmerhorst FM, Bloemenkamp KW, Rosendaal FR, Vandenbroucke JP. Oral contraceptives and thrombotic disease: Risk of venous thromboembolism. Thromb Haemost 1997; 78: 327-333.

27. Danilenko-Dixon DR, Heit JA, Silverstein MD, Yawn BP, Petterson TM, Lohse CM, et al. Risk factors for deep vein thrombosis and pulmonary embolism during pregnancy or post partum: A populationbased, case-control study. Am J Obstet Gynecol 2001; 184: $104-$ 
110.

28. Pahor M, Guralnik JM, Havlik RJ, Carbonin P, Salive ME, Ferrucci $\mathrm{L}$, et al. Alcohol consumption and risk of deep vein thrombosis and pulmonary embolism in older persons. J Am Geriatr Soc 1996; 44: $1030-1037$.

29. Kawasaki T, Kambayashi J, Sakon M. Hyperlipidemia: A novel etiologic factor in deep vein thrombosis. Thromb Res 1995; 79: $147-$ 151.

30. Lippi G, Brocco G, Manzato F, Guidi G. Relationship between venous thromboembolism and lipid or lipoprotein disorders. Thromb Res 1999; 95: 353-354.

31. von Depka M, Nowak-Gottl U, Eisert R, Dieterich C, Barthels M, Scharrer I, et al. Increased lipoproteina levels as an independent risk factor for venous thromboembolism. Blood 2000; 96: 3364-3368.

32. Sakuma M, Nakamura M, Nakanishi N, Miyahara Y, Tanabe N, Yamada $\mathrm{N}$, et al. Inferior vena cava filter is a new additional therapeutic option to reduce mortality from acute pulmonary embolism. Circ J 2004; 68: 816-821.

33. Lilienfeld DE. Decreasing mortality from pulmonary embolism in the United States, 1979-1996. Int J Epidemiol 2000; 29: 465-469.

34. Stein PD, Kayali F, Olson RE, Milford CE. Pulmonary thromboem- bolism in Asians/Pacific Islanders in the United States: Analysis of data from the National Hospital Discharge Survey and the United States Bureau of the Census. Am J Med 2004; 116: 435-442.

35. Sakuma M, Okada O, Nakamura M, Nakanishi N, Miyahara Y, Yamada N, et al. Recent developments in diagnostic imaging techniques and management for acute pulmonary embolism: Multicenter registry by the Japanese Society of Pulmonary Embolism Research. Intern Med 2003; 42: 470-476.

36. Kuriyama T, Sakuma M, Tanabe N, Yamada N. Comprehensive and integrated approach to pulmonary thromboembolism. Respir Res 2005; 24: 730-740 (in Japanese).

37. Statistics and Information Department, Minister's Secretariat, Ministry of Health, Labour and Welfare. Patient Survey 2002. Tokyo, 2004.

38. Colantonio D, Casale R, Natali G, Pisqualetti P. Seasonal periodicity in fatal pulmonary thromboembolism. Lancet 1990; 335: 56-57.

39. Stein PD, Kayali F, Beemath A, Skaf E, Alnas M, Alesh I, et al. Mortality from acute pulmonary embolism according to season. Chest 2005; 128: 3156-3158.

40. Sakuma M, Kumasaka N, Shirato K. Pulmonary thromboembolism: Is the incidence accurate? Jpn Circ J 1999; 63: 825-827. 